\section{The Paluxy River mystery}

SiR-The article "On the Tracks of Men and Money" by Tony Thulborn (Nature 320,308 ; 1986) contains many inaccuracies on a subject that cries for clarity. The presumed occurrence of both human and dinosaur tracks in the Lower Cretaceous Glen Rose limestone in central Texas has for over a decade been the favourite illustration of the creation model, while being, as Thulborn personally admitted to me, "the evidence evolutionists feared the most".

It is true, as Thulborn stated, that, at a January 1986 lecture at the University of New South Wales, I called attention to recent changes in the nature of the tracks which bring into question the original interpretations by myself and others. Having been involved in this project for a decade and having written the definitive book on the subject, I did not find this comfortable, but as an empiricist and honest man, I dared not do less. Even though Thulborn calls the present nature of the tracks "embarrassingly obvious" and the process by which they changed "well known", the truth is, evidently, that an unprecedented geological phenomenon has taken place which is, as yet, only poorly studied and less well understood.

Somehow, since 1984, surface stains in the shape of tridactyl dinosaur prints have appeared, surrounding many of the eroded remnants of elongated tracks once interpreted as human-like. In almost al cases, these stains are not associated with any impression in the rock - they are a coloration phenomenon only. In some cases, the stain ingores the "mud up-push" surrounding the human-like impressions.

Neither my two field trips to the Paluxy in the fall of 1985, nor the analysis of samples taken, answer all the questions. There are only two possibilities: (1) an, as yet, undeciphered geological process partially obscured portions of the tracks of a previously unknown dinosaur which walked in an atypical plantigrade fashion, or (2) that someone has fraudulently altered the appearance of the tracks.

I emphasize that I have seen no direct evidence of fraud. I plan to continue my research once water levels are lower, to gain a more complete understanding, but meanwhile I have encouraged creationists to refrain from using the Paluxy as an antievolutionary argument.

Thulborn and other evolutionists are rushing to embrace this evidence, relishing the fact that the tracks, once thought to be human, now appear reptilian. But hitherto, the usual evolutionists' explanation has been that the markings were not tracks at all. The 1986 booklet Creationism, an Australian Perspective by the Australian Skeptic Society implied that I had carved some of them. Others have claimed they were scour marks, eroded potholes, worm burrows or creationist footprints in the river-bottom mud. After studying both the present nature of the prints and photographs of their nature when first discovered, I am convinced that the original interpretation was not only valid, but arguably the best.

Thulborn, president and founder of the Australian Association for the Protection of Evolution (APE), is also less than objective when he repeats the Skeptics' charge of financial impropriety on the part of the Creation Science Foundation (CSF) of Australia. He claims "CSF still declines to give a detailed explanation" of the whereabouts of $\$ 92,000$. However, he should know (I was standing next to him when the president of CSF explained it to him) that an employee of the investment company in which the money had been placed had embezzled from many accounts, including that of CSF, and that the authorities had frozen the remaining assets. Court cases are now in progress. So far CSF has received only a portion of its money back.

Likewise, Thulborn repeats the charge that federal money had wrongly been given to CSF in the form of an "export market development grant". My understanding is that the Australian government financially encourages companies and organizations that export products to be sold overseas; CSF has recently begun to publish and print locally a magazine and other publications which are primarily sold in North America and Europe and, as such, is eligible for such an export development grant.

Institute for Creation Research,

10946 Woodside Avenue North,

Santee, California 92071, USA

SIR--Tony Thulborn reports (Nature 320; $308 ; 1986)$ that Robert Morris now admits that the "human" footprints on those of big dinosaurs in Cretaceous limestones, Paluxy River, Texas, were those of smal three-toed dinosaurs. Additional news is now available from San Diego, California, that the fake exhibit at the Institute for Creation Research, showing an 80million-year-old human being beside a dinosaur" , has been "closed for revision", and that the "casts" have been removed. Will there be a revision of Dry Bones'?

There is more joy, among evolutionists, over one sinner that repenteth than over ninety and nine that are too brazen to repent. Can we hope that other creationist intellectual atrocities may be abjured by their perpetrators? Examples are misrepresentations of the second law of thermodynamics and of isotopic dating, claims for variability of the speed of light, and engagement, by good and bad angels, in their own form of star wars ${ }^{1}$.

Many evolutionists will be glad to help the creationists put their house in order, even at the expense of its disappearance into thin air.

Thomas H. Jukes

Department of Biophysics and

Medical Physics,

University of California,

Berkeley, California 94720, USA

1. Jukes, T.H. Nature 308, 390-400 (1984).

\section{Cometary first}

SIR-The magnificent 15 May 1986 issue of Nature containing the first results from the spacecraft voyages to comet Halley was marred by an unfortunate lapse in the Editorial (p. 366) by John Maddox entitled "First journey to a comet". For the record, the first encounter took place on 11 September 1985 when the International Cometary Explorer passed 7,800 km tailward of the nucleus of comet GiacobiniZinner. Of the missions to comet Halley, only Giotto came closer to the nucleus.

The field of cometary research has been advanced in 1985 and 1986 by a massive effort from a variety of disciplines. We applaud the work of the Giotto, Sakigake, Suisei and Vega projects for their pivotal contribution. However, appreciation of this achievement does not require a revision of history.

JOHN C. BRANDT ROBERT W. FARQUHAR TYCHO T. vON ROSENVINGE International Cometary Explorer, NASA-Goddard Space Flight Center, Greenbelt, Maryland 20771, USA

\section{Safe nuclear energy}

SIR-The important lesson from the Chernobyl disaster is that the best brains in the world are needed urgently to work on developing safe nuclear energy, and that the warnings of these scientists must be heeded even when they say things that their governments and the nuclear power industry do not like. Unfortunately, one of the best brains in the nuclear safety business has been out of the action for several years. Andrei Sakharov has been isolated, harassed and prevented from contributing to this important effort because he says things that his government does not like.

If General Secretary Gorbachev is really serious about the need for a collective world effort to make nuclear energy safe, he should bring this great pioneer of nuclear safety back into the mainstream of nuclear research.

HARRY J. LIPKIN

High Energy Physics Division, Argonne National Laboratory, 9700 South Cass Avenue, Argonne, Illinois 60439, USA 